\title{
The Model of Bioethics as "Semiotic Attractors" for Diagnosing Innovative Strategies of Training Specialists for NBICS-Technologies Niche
}

\author{
Irina V. Melik-Gaykazyan ${ }^{1, a}$, Maria V. Melik-Gaykazyan², Tamara V. Mescheryakova ${ }^{1}$, Nadezhda S. Sokolova ${ }^{2}$ \\ ${ }^{1}$ Tomsk State Pedagogical University, 634061 Tomsk, Russia \\ ${ }^{2}$ National Research Tomsk Polytechnic University, 634050 Tomsk, Russia
}

\begin{abstract}
Authors interpret bioethics' models as a fixation of the new symbolism in which sociocultural systems expressed its response to impact of technologies standardizing the image of a human being. At the moment it is NBICS technologies that are responsible for this impact. Convergency of these technologies' goals makes education responsible for adjustments of the future states of culture formed by NBICS-technologies. The possibility of this adjustment provided by the fact that training of specialists for the NBICS-technologies niche as the primary resource of those technologies is processed in the space of educational systems. The article reveals the structure of this space; bioethics' models are distributed in the context of this structure and proofs produced for understanding the semiotic essence of the phenomenon of education. These conceptual suggestions shape the original method of semiotic diagnostics of innovative educational strategies based on interpretation of bioethics' symbolism as "semiotic attractors" of knowledge management related to convergent technologies.
\end{abstract}

\section{Introduction}

NBICS-technologies [1] constitute the forefront of modern innovations. These technologies are based on the interdisciplinary combination of results of research in both humanities and fundamental sciences [2-3]. In its turn, goals of NBICS-Technologies' further development determine the strategies of scientific research and training of specialists in corresponding niches. High economical efficiency untwist the "University-IndustryGovernment" [4] spiral in an unprecedented pace and this spiral becomes the "genetic code" of all innovations. The innovations' rate and nature cause a complex of problems that can be described using a metaphor, which allows escaping the establishment of the complex structure of NBICS-Technologies' inter-relations. Vividly the essence of these technologies can be expressed in the following way: all the power of fundamental sciences' results is concentrating for the aimed shot using the single shell-technology. But when it hits the target it disintegrates into multiple parts-shells, each of which moves by its own trajectory to the new targets and as a result it changes all the socio-cultural landscape radically and irreversibly. The given artillery metaphor allows if not understanding but feeling the power of self-organizing technologies' influence on routine life of human, because it is corporeality and conscience of the very human that is "at the gunsight" [5]. Thus, comprehension of inter-relation of the procedures turns into extremely important point. The procedures are: 1) a humanitarian review of consequences of NBICS-technologies' implementation [5]; 2) an ethical review of experiments with participation of human beings in the course of those technologies elaboration [6-7]; 3) a socio-cultural review of humanitarian education's content aimed at specialists prepared for these technologies [8-13]. The problem of the knowledge management related to NBICStechnologies stimulates a convergent nature of all creations and its implementations. It makes "the firing zone" narrow and resulted in shaping of either some abstract anthropological image for all technologies' subjects or divided images of the ones under test and the testing ones. Solution of this question is up to bioethics, because its bio-medical industry and social institutions of health care became the primary "consumers" of NBICS-technologies [5, 14-17].

In the work we will proceed from models of bioethics suggested by R.M. Veatch during the period he considered a revolutionary for medical ethics [18] as well as from the comprehensive description of bioethics belonging to H. Tr. Engelhardt Jr. - "bioethics as a

\footnotetext{
$\overline{{ }^{a} \text { Corresponding author: melik-irina } @ y a n d e x . r u ~}$
} 
plural noun" [19]. We consider the reproach, flung at bioethics just recently, to be very remarkable. It makes the title of T. Chamber's book, "The Fiction of Bioethics" [20]. Its author came to this conclusion on the grounds that it is only the modern fiction that deals with the real problems of bioethics while "philosophers contemplate fictional accounts" [20].

This verdict is matched with our hypothesis on bioethics fixing the new symbolism, generated by NBICS-technologies, while the philosophy defect is its inability to engage precision methods of natural science to measure this symbolism in a relevant way.

\section{The problem of correlation between plurality and singularity in bioethics and education}

Models of ethical medicine were developed by R. M. Veatch on the grounds of summarizing practical situations started to arise under the influence of different interpretations of ethically acceptable doctor-patient relationship, in which the one is under test and the other is a testing one $[18,21]$. It is worth emphasizing that it was summarizing to empirical experience and was related to communicative roles in the whole world of biomedical practice. While the requirements to the quality of medical care and medical duty were equal, communicative doctor-patient relationships were multiple:

1. a competent doctor vs. a profane patient (Priestly Model);

2. equitable colleagues or "friends" (Collegial Model);

3. a doctor-researcher vs. a patient solely responsible for adopting the role of a high-tech procedure "consumer" (Engineering Model);

4. partners in a joint treatment or research, similar to people married by love, and of convenience (Contractual Model).

It is clear the same individual being a doctor and/or patient in different situations can play any of the roles listed above. But if an individual has a choice for migration all along the spaces of bioethics' models, an organization is unable to collect all these models "under one roof". It results in a problem for knowledge management because, depending on the models adopted, the knowledge spiral will untwist in a specific way. Moreover, the new knowledge in the learning organization will be actualized in a different way [22]. However, in actuality of managerial decisions for a certain organization plurality of individual, preferences often will be absorbed by unambiguous understanding of what is the good, good society, true knowledge and right living. When this unambiguity meets the actual life philosophy that was called to explain the phenomena listed, it turns into a "fiction", and in the frameworks of specific concepts, they are very rarely considered "as a plural noun". For decision-makers there is always something better, truer, righter. By the way, bioethics' models, developed by R. M. Veatch, were presented to defend benefits of a Contractual Model among other ones. Analytical structures ordering pluralism of conceptions are able to overcome prejudices and preferences. Before switching to these structures let us settle the phantom conditions of unambiguity (Table 1), which is actual in the content of convergent technologies standardizing the human being.

Table 1. Fictional conditions of singularity in bioethics and education.

\begin{tabular}{|l|l|}
\hline \multicolumn{1}{|c|}{ Bioethics, if } & \multicolumn{1}{c|}{ Education, if } \\
\hline $\begin{array}{l}\text { There were unambiguous } \\
\text { definitions of concepts } \\
\text { "health" and "standard" }\end{array}$ & $\begin{array}{l}\text { There were unambiguous } \\
\text { definitions of concepts } \\
\text { "education" and } \\
\text { "knowledge" }\end{array}$ \\
\hline $\begin{array}{l}\text { All the people would take } \\
\text { their own/another's health } \\
\text { responsibly }\end{array}$ & $\begin{array}{l}\text { All the students would take } \\
\text { their own education } \\
\text { responsibly and all the } \\
\text { teachers take their students' } \\
\text { education and upbringing } \\
\text { responsibly }\end{array}$ \\
\hline $\begin{array}{l}\text { Each patient would have } \\
\text { one disease }\end{array}$ & $\begin{array}{l}\text { Everywhere and always } \\
\text { education would have the } \\
\text { same set of goals, methods } \\
\text { and technologies }\end{array}$ \\
\hline $\begin{array}{l}\text { All methods of treatment } \\
\text { were accessible for all the } \\
\text { patients equally }\end{array}$ & $\begin{array}{l}\text { All methods of education } \\
\text { were accessible for all the } \\
\text { students equally }\end{array}$ \\
\hline $\begin{array}{l}\text { Doctor's actions were } \\
\text { always in accordance with } \\
\text { patient's wishes }\end{array}$ & $\begin{array}{l}\text { Teacher's actions were } \\
\text { always in accordance with } \\
\text { student's wishes }\end{array}$ \\
\hline $\begin{array}{l}\text { Each patient would } \\
\text { understand his/her wishes } \\
\text { and formulate them in a } \\
\text { unambiguous way }\end{array}$ & $\begin{array}{l}\text { Each student would } \\
\text { understand his/her wishes } \\
\text { and formulate them in a } \\
\text { unambiguous way }\end{array}$ \\
\hline $\begin{array}{l}\text { Each patient was always } \\
\text { capable and got no relatives }\end{array}$ & $\begin{array}{l}\text { All the students would have } \\
\text { equal abilities and all the } \\
\text { parents foster their children } \\
\text { in the same way }\end{array}$ \\
\hline $\begin{array}{l}\text { Unbearable pain was } \\
\text { exterminated, each lifetime } \\
\text { was equal and death was } \\
\text { easy }\end{array}$ & $\begin{array}{l}\text { Period of education for each } \\
\text { student were the same and } \\
\text { learning was easy }\end{array}$ \\
\hline
\end{tabular}

Content of Table 1 shows that the problems of bioethics and the theory of education are close. The both of these humanities are based on ethics' ideas [20]. These ideas are ordered and assign their own directions of human aspirations (Table 2).

Table 2. Axiological interpretation of ethics' basic ideas [23].

\begin{tabular}{|c|l|l|}
\hline & \multicolumn{1}{|c|}{ Particularism } & \multicolumn{1}{c|}{ Universalism } \\
\hline I & $\begin{array}{l}\text { A human being } \\
\text { contributes to her/his } \\
\text { own goals on the basis } \\
\text { of his/her own } \\
\text { understanding of the } \\
\text { good }\end{array}$ & $\begin{array}{l}\text { A human being } \\
\text { contributes to her/his } \\
\text { own goals on the basis } \\
\text { of what each rational } \\
\text { person considers the } \\
\text { good }\end{array}$ \\
\hline Other & $\begin{array}{l}\text { A human being } \\
\text { contributes to the } \text { other } \\
\text { ones' goals on the basis } \\
\text { of his/her own } \\
\text { understanding of the } \\
\text { good }\end{array}$ & $\begin{array}{l}\text { A human being } \\
\text { contributes to the } \\
\text { other ones' goals on } \\
\text { the basis of what each } \\
\text { rational person } \\
\text { considers the good }\end{array}$ \\
\hline
\end{tabular}




\begin{tabular}{|l|c|c|}
\hline & Utilitarism & Altruism \\
\hline
\end{tabular}

All the space of morality is divided with irresistible limit. The essence of delimitation is either they understand the good as one for all and the universal for all or particular one, i.e. private, varying depending on the ideological choice of personality or individual groups. The second antithesis is the understanding of the right behaviour aimed either at serving the interest of other people or at achieving individual goals and selffulfillment of a personality. Alternative variants of understanding the good and goals of actions shape four basic ethical systems: Altruism, Perfectionism, Hedonism and Utilitarism. Ethics of merciful love and good, ethics of self-perfection, ethics of enjoyment, ethics of use every one of it has equal rights to exist, but every one creates its own program of the moral life, hence, different ideas of fostering, which can lead to different forms of sublimations and deviations.

Considering correlation of goals (Table 1) from the point of view of a doctor or a developer of new technologies, represented in bioethics' models, allow uncovering the following correspondences. An authoritarian role of a doctor in Priestly Model is sanctified with high morals of altruism, while an unbiased role of a doctor/researcher in an Engineering Model gets into intersection of aspirations for individual goals and freedom of individual choice between due and desired. But in the same intersection of hedonism there are efforts and freedom of creativity peculiar to creators of the new knowledge. In this case those who are involved in innovations' promotion of knowledge in other areas will be forced to build collegial relationships from positions of perfectionism, while those who are concentrated on implementation of the new knowledge into technologies, potentially implemented at a wide area, "get" into the ethical frame of utilitarism. At the same time any specialist cannot change his/her personal "ethical clothes" depending on specifics of his/her professional practice. Bioethics' models used to solve the very moral dilemma, when the unambiguously realized doctor's duty changed in a revolutionary way. The solution, obtained by bioethics, is applicable to education of specialists trained for the NBICS-technologies niche, because communicative models are related to the organizational apparatus of the definite innovations' development stage: obtaining the new scientific knowledge, its interdisciplinary promotion, its implementation into a production and humanitarian review of its consequences in the definite cultural context.

\section{Symbolism of bioethics and "semiotic attractors" of innovative educational strategies}

The essence of bioethics' symbolism is that it became a form of culture protecting individuality against any total impact [21]. This symbolism is exceptionally actual for understanding semiotic bounds related to innovative educational strategies. Given bounds show its worth within a frame of reference determined in Table 2. The presented semantic of goals forms two axes. The axis "Freedom to understand what is the good"/"dependence on understanding of the good by others" sets a horizontal division, while the axis "activity as a contribution to its own goals/passivity as a contribution to others' goals" sets a vertical division. This co-ordinates shape the model presented in Figure 1.

It is worth mentioning that presented axes look like abscissas and ordinates only because of picture's sketchiness. Actually, the model is not two-dimensional and flat since "freedom" and "passivity" are not negative values of "dependency" and "activity". It is a fourdimensional phase space of education containing attractors shaped by NBICS-technologies' goals. Areas of these attractors asymptotically approach the very axes, i.e. they are not placed at the "central" locuses of quadrants corresponding to "extremums" of its moral grounds. At the same time development of NBICStechnologies require that the context of its creation would be morally defined since each novation will be met with a bioethics' review protecting individuality

Activity

(contribution to its own goals)

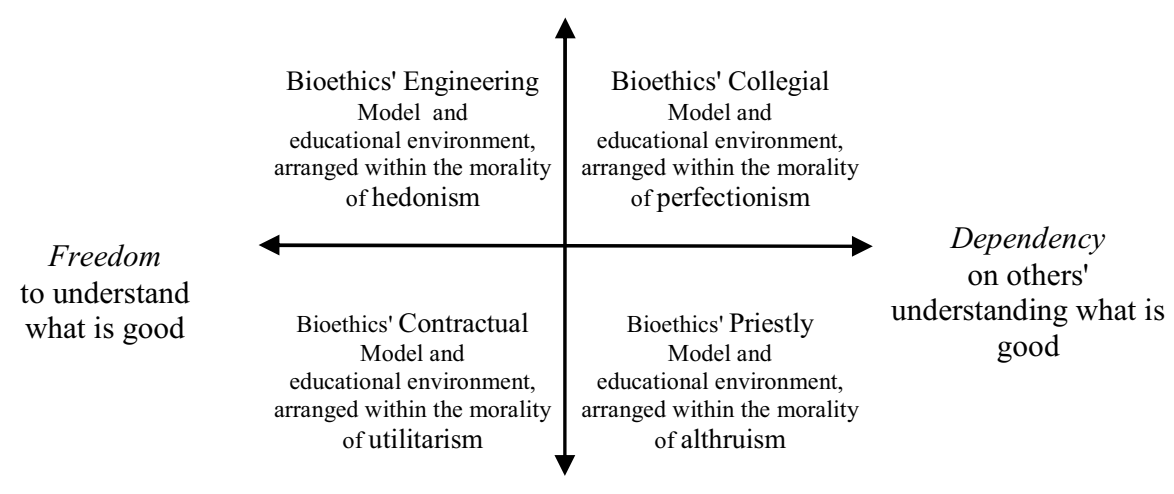

Passivity

(contribution to others' goals)

Fig. 1. The distribution model for goals of innovative strategies intended for training NBICS-technologies specialists. 
modifications of it and manipulations with it. These concerns of bioethics correlate with many trends in symbolism of modern culture - medicinization of a cultural language [24], bioesthetics, hybridization of natural and artificial forms of life in the art [25], embodiment of social altruism's images in new types of volunteerism [26]. All listed is the semiotic expression of social responses to the impact of NBICS-technologies. The same responses are pointers at those borderlands on which they lose the feeling of connection with cultural codes and understanding of the intellectual traditions' "language" nurtured in the culture. At all ages and all cultures, education was the connecting link of the past and the future. Indeed, this is the link not between the actual past and future, but between symbols of the past (because in fact nobody remembers the distant past) and symbols of the future (since nobody knows the actual future yet). It turns education into interpretation of such symbols from a position of the present time which uncovers the semiotic essence of education. The given substance allows assuming that detection of "semiotic attractors" is also applicable to determination of goals of innovative educational strategies leaving behind the rate of NBICS-technologies' novations. Such definition would be optimal if humanities had experience of numerical measurements since methods of non-linear dynamics for determining attractors are numerical methods. It is strangely enough, but this problem with numerical measurements can be solved exactly for elaboration of strategies related to training specialists for the NBICS-technologies niche.

Therefore, moral grounds of educational environment (Figure 1) set the semantics - a communicative system, illustrated by the bioethics' model, determine the syntactics - the prognostic potential of knowledge management in transdisciplinarity of convergent technologies, set the pragmatics. It is beyond exception that education is the information system, in which all the stages of the information process take place - from generation of information, while science creates new knowledge and encodes it into methodical support of the course of studies, to replication of operator work's results, while preparing graduates. Structural levels of the educational system set the channels of information transmission, which characteristics are defined by communication channels distributing roles of education subjects. Similar characteristics of the information system integrate all the components of knowledge management. Information theory is rich in developed methods of many characteristics' calculation. In the stated semiotic nature of education we use three characteristics: value of information (dependency from probability of reaching a goal), quantities of information and information efficiency (the value of quantities of the information ratio). Distribution of goals, presented at Figure 1, points at possibility of using the value of the information characteristics, such as the communicative structure and the volume of the course of studies, to use quantities of the information characteristic and demands of a specialist to use the information efficiency characteristic. Undoubtedly, the usage of each characteristic will not be a single one, since each of semiotic components has multiple embodiments in educational systems. To determine attractors on the grounds of information characteristics, the fundamental point will consists in that all these characteristics are probabilistic. Hence, its values are ranged from zero to one. It allows using a vector value, which is necessary for determining the attractor. In the observed case this role is played by the vector of a unit circle. "The start" of such vector is placed at the intersection of axes and its value is defined by values of probabilistic characteristics of information, while the location of "the edge" may predict the measure of correlation between goals of the offered education and the "product" formed by this education.

It is essential to emphasize one more aspect of presented semiotic diagnostics. The cultural result of education depends on how the format of its upper level is adjusted, since exactly its requirements of "input control" determine parameters of lower levels' results. Attractors, established in the educational space, are able to point at actual aspirations of NBICS-technologies by locus, in which specialists' training will be of demand. And the most important moment is which will be the hierarchy of such education's priorities. The locus (Figure 1) of Priestly Model corresponds with interests of education aimed at maintaining traditions. In the most of its manifestations this educational environment achieve the maximum quality, but due to its traditionality it is of little demand in the NBICStechnologies niche. The locus, following perfectionism ideas, shape leader qualities and aim at sustainable achievement of personal success in the changing social conditions. Correspondence of this locus to the Collegial Model manifests itself in firmly acquired skills for teamwork. The mood of this educational environment is in high demand for training specialists involved in promotion of innovations and implementation of new ideas. As for creators of ideas and developers of custom solutions, they are shaped in hedonism based environment, since the hard path of creativity may be mastered by the personality able to enjoy this activity. However, concentration at creative enthusiasm is accompanied with indifference to the interests of others. This character at the Engineering Model is met suspiciously by bioethics. The freedom to decide individually what is good contains the threat of many deviations [20]. In the context of bioethics' purposes aimed at prevention of negative consequences caused by unexampled innovations, the most preferable is the locus of the Contractual Model, since all interests of NBICStechnologies' subjects are assumed to be equal and fixed by agreements. The disadvantage is each particular problem is solved in a situational way that contradicts the interests of S-technologies as it restrains the rate of its dynamics. Therefore, the cultural tradition sees the top of education in the contexts of altruism The science associates its ascents with the creative origins of the Engineering Model. The convergent technologies 
suppose to reach their future heights on the grounds of solidarity of potentials inherent to the Collegial Model, while bioethics put its protective functions on the resources of the Contractual Model. The observed distribution of requirements to the development of education convinces of the absence of the dominating strategy and instability of general dynamics. We suggest the conceptual solution of this problem. It is necessary to apply bioethics' symbolism expressing a response of culture to the impact of NBICS-technologies for semiotic diagnostics of innovative educational strategies' goals.

\section{Acknowledgment}

The results were obtained in the frameworks of RFBR project №14-06-00440 - "Development of Ways to Use Research Methods of Nonlinear Dynamics for the Detection of the Social System of Self-organization of Attractors"; RHF project № 15-03-00598 - "Bioethics: Creation of the New Symbolism”; project № 155 "Methodology of the Modeling the Semiotic Mechanisms of Management of Educational Systems of Nonlinear Dynamics" of the State assignment for Tomsk State Pedagogical University.

\section{References}

1. M. Roco, W. Bainbridge, Converging Technologies for Improving Human Performance: Nanotechnology, Biotechnology, Information Technology and Cognitive Science. Dordrecht: Kluwer Academic Publishers (2003)

2. NRC, Research Universities and the Future of America: Ten Breakthrough Actions Vital to Our Nation's Prosperity and Security, Washington: The National Academies press (2012)

3. NRC, Convergence: Facilitating transdisciplinary integration of life sciences, physical sciences, engineering, and beyond, Washington: The National Academies press (2014)

4. H. Etzkowitz, The Triple Helix: University-IndustryGovernment Innovation in Action, N.Y. \& London: Routledge (2008)

5. E. Grebenshchikova, International Journal of Technoethics, 7(1), 77-84 (2016)

6. J. Illes, S. Bird, Trends in Neuroscience, 29(9), 511517 (2006)

7. A. L. Allen, N. K. Strand, Trends in cognitive sciences, 19(10), 549-551 (2015)

8. S. Schicktanz, M. Schweda, B. Wynne, Medicine, Health Care and Philosophy 15(2), 129-139 (2012)

9. J. Ives, Bioethics, 28(6), 302-312 (2014)

10. A. Petersen, Social Science \& Medicine, 9, 264-270 (2013)

11. Ten H. Have, B. Gordijn, Medicine, Health Care and Philosophy, 15(2), 99-101 (2012)

12. X. Liu, Higher Education of Social Science, 7(3), 76-79 (2014)

13. B. Prainsack, A. Buyx, Bioethics, 26(7), 343-350 (2012)
14. J. Abelson, E. A. Blacksher, K. Li, S. Boesveld, S. Goold, Journal of Public Deliberation, 9(1), 4-30 (2013)

15. C. Grady, The American Journal of Bioethics, 13(1), 8-10 (2013)

16. J. Millum, B. Sina, Journal of Empirical Research on Human Research, 9, 2-11 (2014)

17. A. Matar, S. Garner, J. Millum, B. Sina, H. Silverman, Journal of Empirical Research on Human Research, 9, 12-23 (2014)

18. R. M. Veatch, The Hastings Center Report, 2(3), 5-7 (1972)

19. H. T. Engelhardt jr., The Foundations of Bioethics, 2nd ed., New York, (1996)

20. T. Chambers, The fiction of bioethics, London: Taylor\&Francis Ltd. (2015)

21. T. V. Mescheryakova, I. V. Melik-Gaykazyn, Scholae. Ancient Philosophy and the Classical Tradition, 9(1), 36-45 (2015)

22. S. Panahi, J. Watson, H. Partidge, Journal of Information Science, 12, 0165551515598883 (2015)

23. R. G. Apresyan, TSPU Bulletin 1, 89-94 (2008)

24. E. Parens, Bioethics, 27(1), 28-35 (2013)

25. A. Munster, Art in the biotech era. Adelaide: “Experimental Art Foundation”, 14-21 (2008)

26. M. Gorbuleva, I. Melik-Gaykazyan, M. MelikGaykazyan, Sociological Studies, 4, 152-153 (2016) 